\title{
Antifungal, antibacterial and antimycobacterial activity of Entada abysinnica Steudel ex A. Rich (Fabaceae) methanol extract
}

\author{
Richard M. Mariita, John A. Orodho', Paul O. Okemo, Paul K. Mbugua \\ Department of Plant and Microbial Sciences, ${ }^{1}$ Educational Management, Policy and Curriculum studies, Kenyatta University, \\ P.O. Box 43844-00100, Nairobi, Kenya \\ Submitted: 17-02-2010 \\ Revised: 06-06-2010 \\ Published: 19-07-2010
}

\section{A B S T R A C T}

The purpose of the study was to investigate the antifungal, antibacterial and antimycobacterial properties of methanol extract of Entada abysinnica steudel ex. A. Rich (Fabaceae) leaves used by herbalists from the Lake Victoria region, Kenya. The extract was tested against four strains of mycobacteria (Mycobacterium tuberculosis, Mycobacterium kansasii, Mycobacterium fortuitum, and Mycobacterium smegmatis) using BACTEC Mycobacteria Growth Indicator Tube (MGIT) 960 system and the proportional method. Standard procedures were used to determine the zones of inhibition, minimum inhibitory concentrations (MICs) and minimum bactericidal/fungicidal concentrations (MBCs/MFCs) for Candida albicans, Salmonella typhi, Staphylococcus aureus, Pseudomonas aeruginosa, Escherichia coli, and Klebsiella pneumoniae. The extract showed activity against some mycobacteria strains, especially M. tuberculosis. It also showed strong antimicrobial activity (zones of inhibition were between 9.00 and $14.10 \mathrm{~mm}$ ) against $C$. albicans, Sa. typhi, and St. aureus. The extract gave a better zone of inhibition against $C$. albicans than fluconazole whose zone of inhibition was $13.00 \mathrm{~mm}$. The MICs and MBCs for $C$. albicans and Sa. typhi were good. The crude extracts were also analyzed for the presence of phytochemicals. Phytochemical screening indicated that the extract most abundantly contained tannins, saponins, and flavonoids. The data suggest that the methanolic leaves extract of $E$. abysinnica could be a rich source of antimicrobial agents, especially antifungals. The results further show that there is some merit in the use of the plant in alternative medical practices. However, bioassays of isolated compounds are underway and will be reported during subsequent communications.

Key words: Antifungal, antibacterial, antimycobacterial, Entada abysinnica, methanol extract

\section{INTRODUCTION}

From the prehistoric times, man has used plants to alleviate and treat diseases. ${ }^{[1-3]}$ The World Health Organization (WHO) estimates that up to $80 \%$ of the world's population relies on traditional medical practices for some aspect of primary health care. ${ }^{[2]}$ The reliance of such a large portion of the population on traditional medicine can be attributed to a number of factors: relatively good accessibility to the plants, affordability, and extensive local knowledge and expertise amongst the local communities. ${ }^{[4]}$

Despite the availability of modern medicines, most communities (either by choice or for lack of economic

Address for correspondence:

Prof. Paul O. Okemo, Department of Plant and Microbial

Sciences, Kenyatta University, PO Box 43844-00100,

Nairobi, Kenya. E-mail: okemo1952@yahoo.com

DOI: $10.4103 / 0974-8490.65511$ resources) still use and retain an extensive pharmacopoeia of native plants. ${ }^{[1,4-6]}$ In recent years, the interest in folk medicine has highly increased. ${ }^{[5]}$ Plants have been used as a source of medicine to treat different ailments in East Africa and particularly Kenya ${ }^{[6]}$ Current estimates indicate that over 400 plant species are used for the management of common diseases in East Africa.

Plants produce a variety of secondary metabolites that have long been of interest to man. In recent years these are used, either directly as precursors or as lead compounds, in the pharmaceutical industry and it is expected that plant extracts showing target sites other than those used by antibiotics will be active against drug-resistant microbial pathogens. ${ }^{[7]}$ Entada abyssinica steudel. ex A. Rich (Fabaceae) is a tree that is found all over tropical Africa. The plant has been used for the treatment of bronchitis, coughs, and to alleviate arthritic pains. ${ }^{[8]}$ It is also used in the treatment of miscarriage, fever and abdominal pain. The juice of E. abyssinica is employed as an instillation for eye inflammation. ${ }^{[8]}$ 
Diseases like tuberculosis are a major global health problem complicated by escalating rates of antibiotic resistance with an estimated 8-9 million new cases occurring worldwide annually. ${ }^{[9]}$ The issue has become even more so as a result of increasing drug resistant strains and manifestations of HIV/AIDS which complicate efforts to control the disease. ${ }^{[10]}$ As tuberculosis spreads through the populations, there is also increased incidence of other infections. Currently, there is a growing disease burden worldwide from water, sanitation, and hygiene, which account for $4 \%$ of all deaths. ${ }^{[3]}$ Diarrheal diseases are a major problem in all African countries especially in the tropical areas. ${ }^{[3,11]}$ Other infective agents such as Pseudomonas aeruginosa, Candida albicans, and Staphylococcus aureus are now common in healthcare settings, especially in immunosuppressed individuals and other highly vulnerable patients. ${ }^{[1]}$ There is therefore an urgent need to develop more effective drugs to handle the expanding problem of drug- and multi-drug resistance.

\section{MATERIALS AND METHODS}

\section{Collection and identification of plant materials}

Fresh leaves of E. abysinnica Steudel ex A. Rich (Fabaceae) were collected from Bondo (Sakwa) in western Kenya, based on the ethnobotanical survey that was carried out. The plant was authenticated by a plant taxonomist, Mr. Lucas Karimi from the Department of Pharmacy and Complimentary Alternative Medicine (CAM), Kenyatta University, Nairobi, Kenya. The Voucher specimen of collected plant is deposited at the Kenyatta university herbarium for reference.

\section{Drying, grinding, and methanolic extraction}

The plant samples collected were shade dried and ground using hammer type milling machine (Meecan, CM/L1364548, Gujarat, India) at the Department of Pharmacy/ CAM, Kenyatta University. The powdered material was transferred into and extracted in the soxhlet extractor using methanol for 72 hours. ${ }^{[12]}$ The extracts were filtered through a Whatmann filter paper No. $42(125 \mathrm{~mm})$ and concentrated using a rotary evaporator (Laborota 4000, SN 090816862 , Germany) with a water bath set at $40^{\circ} \mathrm{C},{ }^{[13]}$ then dried in a dessicator over anhydrous $\mathrm{CuSO}_{4}$. The powdered residue were transferred into vials and stored at $4^{\circ} \mathrm{C}$ till the time of analysis.

\section{Test cultures}

The four species of mycobacteria used for the assays were obtained from the Center for Respiratory Diseases Research (CRDR), KEMRI, Kenya, and included Mycobacterium tuberculosis, Mycobacterium kansasii, Mycobacterium smegmatis, and Mycobacterium fortuitum. Rejuvenation was done on the Lowenstein Jensen (LJ) slants for 14 days at $37^{\circ} \mathrm{C}$ using standard procedures. The test cultures for general antibacterial and antifungal activity were obtained from Kenyatta National Hospital in Nairobi, Kenya and included Salmonella typhi (clinical isolate), Klebsiella pneumoniae (clinical isolate), P. aeruginosa (ATCC 25852), Escherichia coli (ATCC 25922), and St. aureus (ATCC 20591), while C. albicans (ATCC EK138) was used for antifungal activity tests.

\section{Antimycobacterial testing \\ Proportional method (use of Lowenstein Jensen slants)}

The extracts were dissolved in $0.01 \%$ dimethyl sulfoxide (DMSO) (so as to get the desired final concentrations of 2,1 and $0.5 \mathrm{mg} / \mathrm{ml}$ ) and added to the $\mathrm{LJ}$ medium before heating at $85^{\circ} \mathrm{C}$ for 50 minutes in a slanting position. The LJ slants were then stored at room temperature for 48 hours to exclude contamination. ${ }^{[14,15]}$ The tubes were inoculated with strains of mycobacteria. A stock solution of $2.0 \mathrm{mg} /$ $\mathrm{ml}$ of isoniazid was used as positive control and $0.01 \%$ DMSO as the negative control.

Isolates of the four species of mycobacteria were prepared for drug susceptibility testing. Using a $3 \mathrm{~mm}$ internal diameter (24 standard wire gauge) wire loop, about $4 \mathrm{mg}$ fresh culture was scraped from LJ medium into $500 \mu \mathrm{l}$ sterile distilled water in a bijou bottle with five glass beads and vortexed for about 30 seconds to homogenize. The suspension was made up to $4 \mathrm{ml}$ volume by adding 3.5 $\mathrm{ml}$ sterile distilled water. The suspension was allowed to settle for about 30 minutes before gently aspirating the upper portion into a fresh bijou bottle. The suspension was further diluted to obtain the turbidity of $0.5 \mathrm{McF}$ arland standard. ${ }^{[14]}$ The prepared culture was inoculated into extract-free and extract-containing LJ slopes and incubated at $35^{\circ} \mathrm{C}$. Growth was recorded weekly (for 6 weeks) as: +++ for confluent growth, ++ moderate growth, + less growth and - for no growth. Cultured tubes were examined visually and sample tubes showing less growth than negative control tubes were considered inhibitory.

\section{BACTEC MIGIT' 960}

The extracts and the drug were prepared just like in the LJ slants. Into the $7 \mathrm{ml} \mathrm{BBL}^{\mathrm{TM}}$ Mycobacteria Growth Indicator Tube (MGIT) ${ }^{\mathrm{TM}}$ tubes, $0.8 \mathrm{ml}$ of a mixture of growth OADC supplement (added to provide essential substances for rapid growth of mycobacteria) and BBL MGIT PANTA (a mixture of antimicrobial agents) was added. Then 1 $\mathrm{ml}$ of the extract was added into the BBL MGIT tubes to attain appropriate concentrations of 2,1 , and $0.5 \mathrm{mg} /$ $\mathrm{ml}$. Then $0.5 \mathrm{ml}$ of the mycobacterium suspension was introduced into the BBL MGIT tubes. The strains included M. tuberculosis (Mtb), M. kansasii (Mk), M. fortuitum (Mf), and M. smegmatis (Ms). The BACTEC MGIT ${ }^{\mathrm{TM}} 960$ system was loaded using manufacturer's instructions at $37^{\circ} \mathrm{C}$. 
Culture vials which remained negative for a minimum of 42 days (maximum 56 days) were removed and recorded as negative, while growth units (GUs) for the positive ones were recorded appropriately. ${ }^{[16]}$

\section{Antibacterial and antifungal testing \\ Disk Diffusion technique}

To evaluate the general antibacterial and antifungal activity of the extracts, disk diffusion (DD) method was used. Filter paper disks $(6 \mathrm{~mm})$ were impregnated with extracts. Mueller Hinton agar and Potato Dextrose Agar (PDA) were prepared using manufacturer's instructions for purposes of culturing the bacteria and fungi, respectively. Normal saline solution was used to dilute a 24-hour culture of the bacterial type culture or clinical isolate to attain a $0.5 \mathrm{McF}$ arland standard. Spread plate method was used to culture $0.1 \mathrm{ml}$ of the microbial suspension that was introduced into the Petri dishes. ${ }^{[1,2,1]}$ Eighteen dry sterile disks ( $6 \mathrm{~mm}$ diameter) were soaked in the plant extract (made by dissolving 300 $\mathrm{mg}$ of the extracts in $1 \mathrm{ml}$ of methanol) and placed on the spread plates at reasonable distances. Disks were impregnated with methanol and dried (negative control) and various positive controls (amoxicillin/ciprofloxacin/ fluconazole) were used. The plates were then incubated at $35^{\circ} \mathrm{C}$ for 24 hours. The procedure was done in triplicate.

C. albicans was cultured by taking $0.1 \mathrm{ml}$ from the broth and spreading on PDA. The culture was incubated at $25^{\circ} \mathrm{C}$ for 72 hours. The cork boarer was used to pick a section of the young mycelium which was placed at the center of the PDA plate and the dry disks which were impregnated with $0.1 \mathrm{ml}$ of the plant extracts placed at a distance around the section of the mycelium. The inoculum was incubated at $25^{\circ} \mathrm{C}$ for 72 hours. Fluconazole and dry disks treated with methanol were also used as positive and negative controls, respectively. All tests were performed in triplicate. Microbial growth inhibition was determined by measuring the zones of inhibition using a transparent ruler.

Determination of minimum inhibitory concentration and minimum bactericidal/fungicidal concentration

The minimum inhibitory concentration (MIC) which is the least amount of antimicrobial that will inhibit visible growth of an organism after an overnight incubation was determined using the microtiter dilution broth method in 96-well microplates. This was done only where the plant extract showed strong antibacterial activity by the disk diffusion method $(\geq 9-15 \mathrm{~mm}) \cdot{ }^{[17]}$ The wells were filled with $50 \mu \mathrm{l}$ of the nutrient broth for bacterial strains and potato dextrose broth for $C$. albicans. The extract was then prepared by taking $300 \mathrm{mg}(0.3 \mathrm{~g})$ of the plant extract and mixing it with $1 \mathrm{ml}(1000 \mu \mathrm{l})$ of dimethyl formamide $(0.01 \%$ DMF) for complete dissolution of the extract. Then, $50 \mu$ l of the plant extract was dispensed into the first well before serial dilutions were done by transferring $50 \mu \mathrm{l}$ of nutrient or potato dextrose broth containing the extract from the first well to the second well, and from the second well to the third well through the fourth well. Exactly $50 \mu \mathrm{l}$ of the test isolate was then dispensed into each well. One well was used as negative control of the growth of the microorganisms in the medium, whereas 50 $\mu l$ of the antibiotic (amoxicillin/ciprofloxacin/fluconazole) was used as positive control. Incubation was done at $37^{\circ} \mathrm{C}$ for 24 hours. The MIC values were determined as the lowest concentrations of the extract capable of inhibiting microbial growth.

For the determination of minimum bactericidal/fungicidal concentration (MBC/MFC), wells where there was no growth were subcultured on nutrient agar and PDA. The lowest concentration of the plant extracts that did not yield any colony on the solid medium (nutrient or PDA agar) after subculturing and incubating for 24 hours for bacterial strains and 72 hours for C. albicans was taken as the MFC/ MBC. All tests were performed in triplicate.

\section{Phytochemical screening}

\section{Test for alkaloids (Wagner's method)}

Alkaloids' presence was determined as follows. Two hundred milligrams of the plant extract was dissolved in $10 \mathrm{ml}$ methanol and filtered. One milliliter of the filtrate was then mixed with six drops of Wagner's reagent. ${ }^{[18]}$ Creamish/brownish-red/orange precipitate indicated the presence of alkaloids. A low $(+)$ reaction was recorded if the addition of the reagent produced a faint turbidity; a moderate $(++)$ reaction was recorded if a light opalescent precipitate was observed; and a high $(+++)$ reaction was recorded if a heavy yellowish-white precipitate was observed. ${ }^{[12,18]}$

\section{Test for cardiac glycosides (Keller-Killani test)}

Five milliliters of each extract was treated with $2 \mathrm{ml}$ of glacial acetic acid containing one drop of ferric chloride solution. This was underlayed with $1 \mathrm{ml}$ of concentrated sulfuric acid. A brown ring at the interface indicated a deoxysugar characteristic of cardenolides. A $(+)$ reaction was recorded when a faint green-blue color was observed (indicating low concentrations of detectable cardiac glycosides); $\mathrm{a}(++)$ reaction was recorded when a medium green-blue color was observed (indicating moderate concentrations of detectable cardiac glycosides); and a $(+++)$ reaction was recorded when a deep green-blue color was observed (indicating high concentrations of detectable cardiac glycosides). ${ }^{[12,18]}$

\section{Test for flavonoids}

Five milliliters of dilute ammonia solution was added to a portion of the aqueous filtrate of each plant extract, 
followed by addition of concentrated $\mathrm{H}_{2} \mathrm{~S}_{4}$. A yellow coloration observed in each extract indicated the presence of flavonoids. The yellow coloration disappeared on standing. A $(+)$ reaction was reported in pale yellow colour, $(++)$ in moderate yellow, and $(+++)$ in strong yellow coloration, indicating low, moderate, or high concentration of flavonoids, respectively, in the plant extract. ${ }^{[12,13]}$

\section{Test for saponins}

To $0.5 \mathrm{~g}$ of extract was added $5 \mathrm{ml}$ of distilled water in a test tube. The solution was shaken vigourously and observed for a stable persistent froth. The frothing was mixed with three drops of olive oil and shaken vigourously after which it was observed for the formation of an emulsion. ${ }^{[12,13]} \mathrm{A}$ $(+)$ sign was recorded when the froth reached a height of $0.5 \mathrm{~cm}, \mathrm{a}(++)$ sign for a height of $0.6-1 \mathrm{~cm}$, and a $(+++)$ sign for a height of more than $1 \mathrm{~cm}$ to indicate low, moderate, or high concentration of saponins, respectively, in the plant extract.

\section{Test for tannins}

About $0.5 \mathrm{~g}$ of the extract was boiled in $10 \mathrm{ml}$ of water in a test tube and then filtered. A few drops of $0.1 \%$ ferric chloride were added and observed for brownish green or a blue-black coloration. ${ }^{[13]} \mathrm{A}(+)$ reaction was recorded when a slight precipitate was observed; a $(++)$ reaction was recorded when a medium precipitate was observed; and a $(+++)$ reaction was recorded when a heavy precipitate was observed. The reactions were used to indicate the presence of different concentrations of detectable tannins, with $(+)$ representing low, $(++)$ moderate, and $(+++)$ high levels of tannins.

\section{Test for terpenoids (Salkowski test)}

To $0.5 \mathrm{~g}$ of each of the extract was added $2 \mathrm{ml}$ of chloroform. Concentrated $\mathrm{H}_{2} \mathrm{SO}_{4}(3 \mathrm{ml})$ was carefully added to form a layer. A reddish brown coloration at the interface indicated the presence of terpenoids. ${ }^{[12,13]}$ A $(+)$ reaction was recorded when a faint reddish brown coloration was observed; a $(++)$ reaction was recorded when a medium reddish brown coloration was observed; and a $(+++)$ reaction was recorded when a deep reddish brown coloration was observed.

\section{RESULTS}

E. abysinnica showed encouraging activity in most of the mycobacteria cultures tested using BACTEC MGIT 960 system [Table 1]. Results were provided as positive/negative and numerical GUs using a non-radiometric evaluation technique. There was complete inhibition (zero GUs) of the mycobacteria strains at 2.0 and $1.0 \mathrm{mg} / \mathrm{ml}$. At 0.5 $\mathrm{mg} / \mathrm{ml}$, there was complete inhibition (zero GUs) of $M$.

\begin{tabular}{|c|c|c|c|c|c|}
\hline & $2.0 \mathrm{mg} / \mathrm{ml}$ & $1.0 \mathrm{mg} / \mathrm{ml}$ & $0.5 \mathrm{mg} / \mathrm{ml}$ & Isoniazid & DMSO \\
\hline $\mathrm{Mk}^{1}$ & 0 & 0 & 1079 & 0 & 745 \\
\hline $\mathrm{Mtb}^{1}$ & 0 & 0 & 0 & 0 & 2002 \\
\hline$M f^{2}$ & 0 & 0 & 18 & 0 & 187 \\
\hline $\mathrm{Ms}^{2}$ & 0 & 0 & 97 & 0 & 2957 \\
\hline
\end{tabular}

tuberculosis as well as appreciable inhibition against $M$. fortuitum (18 GUs) and M. smegmatis (97 GUs). There was no growth (zero GUs) in the positive control (isoniazid), whereas there was growth in the negative control (DMSO) (187-2957 GUs). The extract had strong antimycobacterial activity against $M$. tuberculosis with no growth (zero GUs) in all the concentrations tested. From the proportional method, the culture tubes were examined visually and sample tubes showed no growth in all concentrations of 2.0 and $1 \mathrm{mg} / \mathrm{ml}$. In the concentration of $0.5 \mathrm{mg} / \mathrm{ml}$, however, $M$. tuberculosis was inhibited, whereas there was moderate growth in the slants containing $M$. fortuitum and M. smegmatis. Where there was moderate growth, the extract could still be considered to be inhibitory because there was less growth than in the negative control tubes.

All the extracts showed varying degrees of antimicrobial activity against the non-mycobacterial organisms tested [Table 2]. It showed good antimicrobial activity against C. albicans, Sa. typhi and St. aureus. Against C. albicans, the zone of inhibition was $14.10 \mathrm{~mm}$ against $13.00 \mathrm{~mm}$ of fluconazole. The extract showed strong MICs $(1.875 \mathrm{mg} /$ $\mathrm{ml})$ and MBCs/MFCs $(1.875 \mathrm{mg} / \mathrm{ml})$ against Sa. typhi and C. albicans. With the zones of inhibition of $7.66 \mathrm{~mm}$ and $7.33 \mathrm{~mm}$, there was no appreciable activity of the plant extract against E. coli and K. pneumoniae, respectively.

Further work on preliminary photochemistry revealed the presence of various phytochemicals [Table 3]. The extract showed the presence of flavonoids, saponins, and terpenoids to be most abundant $(+++)$. Other phytochemicals that were present are alkaloids and cardiac glycosides which were abundant $(++)$ and less abundant $(+)$, respectively. The extract tested negative for terpenoids.

\section{DISCUSSION}

The activity of plant extracts against bacteria has been studied for years, but more aggressively during the last three decades. ${ }^{[19]}$ In the present study, the methanolic extract of E. abysinnica was used. The activity of E. abysinnica extracts against mycobacteria strains showed that the plant contains pharmacologically active substances [Tables 1 and 3]. The results were comparable to those of the standard drug (isoniazid) in both the proportional method (LJ slants) 
Table 2: Zones of inhibition, MICs (mg/50 $\mu \mathrm{l})$ and MBC/MFC (mg/50 $\mu \mathrm{l})$ of $E$. abysinnica on various bacterial test cultures

\begin{tabular}{|c|c|c|c|c|c|c|}
\hline & Sa. typhi & St. aureus & E. coli & P. aeruginosa & K. pneumoniae & C. albicans \\
\hline Zones of inhibition $(\mathrm{mm})^{1}$ & 10.33 & 9.66 & 7.66 & 8.33 & 7.33 & 14.10 \\
\hline Zones of inhibition $(\mathrm{mm})^{2}$ & 16.00 & 21.33 & 20.22 & 17.33 & 17.66 & 13.00 \\
\hline Zones of inhibition $(\mathrm{mm})^{3}$ & 6.00 & 6.00 & 6.00 & 6.00 & 6.00 & 6.00 \\
\hline $\mathrm{MICs}^{1}$ & 1.875 & 3.750 & ND & ND & ND & 1.875 \\
\hline $\mathrm{MICs}^{2}$ & 0.46875 & 0.46875 & 0.46875 & 0.46875 & ND & 0.46875 \\
\hline $\mathrm{MICs}^{3}$ & $\begin{array}{c}\text { Growth observed in } \\
\text { all tubes }\end{array}$ & & & & & \\
\hline MBCs/MFCs ${ }^{1}$ & 1.875 & 3.750 & ND & ND & ND & 1.875 \\
\hline MBCs/MFCs ${ }^{2}$ & 0.46875 & 0.46875 & 0.46875 & 0.46875 & ND & 0.46875 \\
\hline $\mathrm{MBCs} / \mathrm{MFCs}^{3}$ & $\begin{array}{c}\text { Growth observed in } \\
\text { all tubes }\end{array}$ & & & & & \\
\hline
\end{tabular}

${ }^{1}$ Produced by E. abysinnica leaves extract; zones of inhibition done in triplicate; ${ }^{2}$ produced by positive controls (fluconazole for C. albicans, zeftazidime for Sa. typhi, ciprofloxacin for K. pneumoniae, and amoxicillin for St. aureus, E. coli, and P. aeruginosa); ${ }^{3}$ produced by negative control (dry disks treated with methanol for zones of inhibition, and DMF for MICs and MBCs/MFCs); ND- not done

Table 3: Preliminary phytochemical screening of the leaves of E. abysinnica

\begin{tabular}{|c|c|c|c|c|c|c|}
\hline & Alkaloids & Cardiac glycosides & Flavonoids & Saponins & Tannins & Terpenoids \\
\hline Most abundant & & & +++ & +++ & +++ & \\
\hline Abundant & ++ & & & & & \\
\hline Less abundant & & + & & & & \\
\hline Not present & & & & & & - \\
\hline
\end{tabular}

and BACTEC MGIT 960 system. The extract appeared particularly promising in its activity against $M$. tuberculosis where it was potent at $0.5 \mathrm{mg} / \mathrm{ml}$. Activity of E. abysinnica against other respiratory problems like bronchitis and coughs has already been reported. ${ }^{[8]}$ Antimycobacterial properties of the medicinal plant could be due to the abundant flavonoids, saponins, and tannins that were found in it [Table 3]. Phytochemical constituents such as tannins, saponins, flavonoids, alkaloids, and several other aromatic compounds are secondary metabolites of plants that serve as defense mechanisms against predation by many microorganisms, insects, and other herbivores. ${ }^{[20]}$ Conventional culture for mycobacteria using proportional method was found to be slow (took an average of 4 weeks and maximum incubation of 9 weeks). The BACTEC MGIT 960 system gave rapid results.

General antibacterial and antifungal results were also promising [Table 2]. The inhibition of C. albicans, St. aureus and $S a$. typhi observed in this study has confirmed the antimicrobial principles in E. abysinnica. A zone of inhibition $\geq 9-15 \mathrm{~mm}$ is an indication of strong antimicrobial activity ${ }^{[17]} C$. albicans was found to be most susceptible to E. abysinnica extract with an inhibition zone greater than that of fluconazole (positive control) [Table 2]. This activity could be attributed to the presence of saponins. Previous investigations on the saponins isolated mainly from Medicago sativa L. have shown that, depending on their structure, they possess antimicrobial activity, principally against plant pathogens and some yeasts pathogenic to humans. ${ }^{[21]}$
For St. aureus, the phenomenon is in accordance with the previous findings from other plant samples, which revealed that antimicrobial activity could be ascribed to different mechanisms of action such as the inhibition against bacterial topoisomerase and efflux pump, other than inhibition against $\beta$-lactamase. ${ }^{[22]}$ Antibacterial activity of saponins against Gram positive bacteria from different plant sources has already been reported. ${ }^{[21]}$

Phytochemical screening of E. abysinnica revealed that flavonoids, saponins, and tannins were most abundant while cardiac glycosides were less abundant. The extract tested negative for alkaloids and terpenoids. Some of this phytochemicals like flavonoids have been known to be antidiarrheal from other studies. ${ }^{[1]}$ The demonstration of antimicrobial activity against Gram-positive and Gramnegative bacteria and $C$. albicans could also be indicative of the presence of broad spectrum antibiotic compounds. ${ }^{[20]}$ Lack of appreciable activity of the plant extract against $E$. coli and $K$. pneumoniae could be due to the fact that they are extended-spectrum $\beta$-lactamase producers (ESBLs) that are being increasingly identified in many parts of the world and are already prevalent in several countries. ${ }^{[23]} \beta$-lactamase is one of the major causes of drug resistance.

\section{CONCLUSION}

The E. abysinnica leaves extract appeared more potent against M. tuberculosis, C. albicans and Sa. typhi. There was also encouraging activity against other test microorganisms. 
This activity could account for its use as herbal medicine. The antimicrobial activities from the present investigation provide important baseline information for the use of $E$. abysinnica for the treatment of infections associated with the studied microorganisms. Further studies should be carried out on the plant in order to isolate, identify, characterize, and elucidate the structure of the bioactive compounds. Toxicological studies should also be carried out.

\section{ACKNOWLEDGMENTS}

The authors acknowledge the funding of the project by Lake Victoria Research Initiative (VicRes), and the inter-university council of East Africa and SIDA/SAREC, through whom the funding was made. Recognition is also given to the Kenya Medical Research Institute's (KEMRI) Centre for Respiratory Diseases' Research (CRDR) for allowing us to work from their Level III tuberculosis laboratory.

\section{REFERENCES}

1. Potterat $\mathrm{O}$, Hamburger M. Drug discovery and development with plant-derived compounds. Prog Drug Res 2008;65:1-73.

2. Akintonwa A, Awodele O, Afolayan G, Coker HA. Mutagenic screening of some commonly used medicinal plants in Nigeria. J Ethnopharmacol 2009;125:461-70.

3. Tetali P, Waghchaure C, Daswani PG, Antia NH, Birdi TJ. Ethnobotanical survey of antidiarrhoeal plants of Parinche valley, Pune district, Maharashtra, India. J Ethnopharmacol 2009;123:229-36.

4. Street RA, Stirk WA, van Staden J. South African traditional medicinal plant trade: Challenges in regulating quality, safety and efficacy. J Ethnopharmacol 2008;119:705-10.

5. Vitalini S, Tomè F, Fico G. Traditional uses of medicinal plants in Valvestino (Italy). J Ethnopharmacol 2009;121:106-16.

6. Jeruto $P$, Lukhoba C, Ouma G, Otieno D, Mutai C. An ethnobotanical study of medicinal plants used by the Nandi people in Kenya. J Ethnopharmacol 2008;116:370-6.

7. Shokeen P, Bala M, Tandon V. Evaluation of the activity of 16 medicinal plants against Neisseria gonorrhoeae. Int J Antimicrob Agents 2009;33:86-91.

8. Olajide OA, Alada AR. Studies on the anti-inflammatory properties of Entada abyssinica. Fitoterapia 2001;72:492-6.

9. Barkan D, Liu Z, Sacchettini JC, Glickman MS. Mycolic acid cyclopropanation is essential for viability, drug resistance, and cell wall integrity of Mycobacterium tuberculosis. Chem Biol
2009;16:499-509.

10. Shamaei M, Marjani M, Chitsaz E, Kazempour M, Esmaeili $M$, Farnia $P$, et al. First-line anti-tuberculosis drug resistance patterns and trends at the national TB referral center in Iraneight years of surveillance. Int J Infect Dis 2009;13:e236-40.

11. Meite S, N'guessan JD, Bahi C, Yapi HF, Djaman AJ, Guina FG. Antidiarrheal activity of the ethyl acetate extract of Morinda morindoides in rats. Trop J Pharm Res 2009;8:201-7.

12. Aiyelaagbe $\mathrm{OO}$, Osamudiamen PM. Phytochemical screening for active compounds in Mangifera indica leaves from Ibadan, Oyo State. Plant Sci Res 2009;2:11-3.

13. Edeoga $\mathrm{HO}$, Okwu DE, Mbaebie BO. Phytochemical constituents of some Nigerian medicinal plants. Afr J Biotechnol 2005;4:685-8.

14. Ani AE, Idoko J, Dalyop YB, Pitmang SL. Drug resistance profile of Mycobacterium tuberculosis isolates from pulmonary tuberculosis patients in Jos, Nigeria. Trans R Soc Trop Med Hyg 2009;103:67-71.

15. Asres K, Bucar F, Edelsbrunner S, Kartnig T, Höger G, Thiel W. Investigations on antimycobacterial activity of some Ethiopian medicinal plants. Phytother Res 2001;15:323-6.

16. Becton. BBL MGIT Mycobacteria growth indicator. Maryland, USA: Dickinson Company; 2007. p. 1-23.

17. Rani $P$, Khullar N. Antimicrobial evaluation of some medicinal plants for their anti-enteric potential against multi-drug resistant Salmonella typhi. Phytother Res 2004;18:670-3.

18. Obdoni BO, Ochuko PO. Phytochemical studies and comparative efficacy of the crude extracts of some homostatic plants in Edo and Delta states of Nigeria. Global J Pure Appl Sci 2001;8b:203-8.

19. Ogundiya MO, Kolapo AL, Okunade MB, Adejumobi JA. Evaluation of phytochemical composition and antimicrobial activity of Terminalia glaucescens against some oral pathogens. Adv Nat Appl Sci 2008;2:89-93.

20. Salama HM, Marraiki N. Antimicrobial activity and phytochemical analysis of Polygonum aviculare L. (Polygonaceae), naturally growing in Egypt. Aust J Basic Appl Sci 2008;3:2008-2015.

21. Avato P, Bucci R, Tava A, Vitali C, Rosato A, Bialy Z, et al. Antimicrobial activity of saponins from Medicago sp.: Structureactivity relationship. Phytother Res 2009;20:454-7.

22. Zuo GY, Wang GC, Zhao YB, Xu GL, Hao XY, Han J, et al. Screening of Chinese medicinal plants for inhibition against clinical isolates of methicillin-resistant Staphylococcus aureus (MRSA). J Ethnopharmacol 2008;120:287-90.

23. Heffernan HM, Woodhouse RE, Pope CE, Blackmore TK. Prevalence and types of extended-spectrum beta-lactamases among urinary Escherichia coli and Klebsiella spp. in New Zealand. Int J Antimicrob Agents 2009;34:544-9.

Source of Support: Nil, Conflict of Interest: None declared. 